\title{
Anthropological Changes of the Person of the Digital Era
}

\author{
Tatyana Leshkevich ${ }^{1 *}$
}

\author{
${ }^{1}$ Southern Federal University, Rostov-on-Don, Russia \\ *Corresponding author. Email: leshkevicht@mail.ru
}

\begin{abstract}
The article discusses the anthropological transformations generated by large-scale digitalization. The main goal of the article is to identify the vectors of the impact of modern technologies on humans. The article analyzes two groups of problems. The first is related to the consideration of the distinctive characteristics of a person of the digital era. The second involves the study of the phenomenon of "convergence of subjectivity" and its main meanings. The methodological strategy is based on the principle of sociocultural determination, which explains the anthropological shift towards the formation of a new type of person. The research also uses the potential an interdisciplinary approach, which allows us to take into account the achievements of the complex of cognitive sciences and social and humanitarian knowledge. The research relies on the theories by contemporary scholars. The author concludes that the digital environment sets the supra-personal scale of control and coercion. Its attribute - technological rationality - is aimed at the use of ready-made information resources. A new type of a person is characterized by the presence of "digital competencies" and is aimed at combining its own intellectual abilities and resources of intellectual systems.
\end{abstract}

Keywords: Anthropological transformations, Digital era, Technological rationality, Convergence.

\section{INTRODUCTION}

The modern civilization has relied on the penetration of digital technologies into all spheres of the human life world. Our contemporary does not think of himself outside of information technology support, and technological achievements are perceived as a significant value of modern way of life. Today it is impossible to talk about understanding of reality without taking into account the rapidly developing intelligent systems and technologies that determine both the present and the future.

It should be emphasized that modern technologies are focused on the symbiosis and convergence of nano-, bio-, info-communication and cognitive processes. The convergence of NBIC- technologies indicates, firstly, an anthropological shift towards hybridization of the human and artifact, and, secondly, the need to study humans in the context of interdisciplinary research. The study of the determining influence of technology on intelligence, physicality and the human psyche allows researchers to talk about a new type of the subject of the XXI century [1]. Among the obvious advantages of technological development are an increase in the pace of online communication, filling the human being with technological achievements and expanding the boundaries of the life world. Online services tend to be widespread. Online resources provide an advanced quick search and help avoid offline barriers. Today, the Internet offers wide opportunities for the distribution of individual activity. However, it should pay particular attention to the negative effects of the digital determination, including the replacement of the real existence with its virtual prototype and causing anthropological transformations. Researchers focus on understanding the complexity of the modern era against the backdrop of the technological revolution and the effects of virtual imitation of reality that determine the worldview [2]. 


\section{BASIC HUMAN IMAGES OF THE DIGITAL ERA: "AGENT OF NETWORK PRACTICES”, "CONTENT VIEWER", "MULTITASKER"}

In the modern period of the pandemic, the massive involvement of people in the digital sphere leads to serious anthropological changes and indicates the transfer of their active abilities to the virtual simulative plane of being. The main hypothesis of our study is related to the assumption that significant anthropological transformations are caused by the substitution of physical reality with its analogue digital projection. The Internet space is characterized by the effect of "multiple birth" of quasi-real events, that exist as symbolic universe. The famous French philosopher J. Baudrillard points to the simulative status of virtual reality. Speaking about the importance of the media in the modern world, J. Baudrillard in his essays "The Gulf War Did Not Take Place" draws attention to the dependence of human consciousness on the interpretation of real events by the media. $\mathrm{He}$ comes to the conclusion that Everything is transposed into the virtual and nowadays virtual has definitively overtaken the actual [3]. It's hard to disagree with these conclusions. Contemporary scholars raise the question of interconnection between the social and the digital; social and humanitarian research tend to extend the scope to include information technologies [4].

Substitution of reality by its given simulative images leads to significant deformations of both human self-consciousness and the system of collective perception. New psycho emotional states arise and behavioral reactions atypical for real life appear. "Face-to-screen" living is a completely different practice for the central nervous system, generating cognitive deformities. The "face-toscreen" existence is accompanied by the passive consumption of online content. A person acts as a "content viewer", an agent of network practices and a multitasker. And in all cases, a person is an object of network manipulation. It is a fact that basic human values are largely determined by the digital world. The digital world gives rise to such values as the "digital image", "digital footprint", "digital success", the amount of "likes" and followers, as well as such notions as Internet slang, "digital skills", network identity, the need for Internet surfing. Digitalization trends are universal. And, as a result, the anthropological transformations caused by them are associated with the generation of a new type of sociality of the Network, which creates invisible connections between people and generates different forms of network subjectivity. The phenomenon of "network collaboration" provides great opportunities to develop new sociability. R. Collins sees "social networks" as a kind of referee in the process of accepting innovations, capable of demonstrating a certain level of resistance [5].

But at the same time, network interactions appear to be a self-sufficient existence, which replaces real-life interactions with simulative analogues. In this regard, it is necessary to pay special attention to multitasking activity, which is typical for a person of the digital age. Digital multitasking is characterized by the readiness to be a part of information events and at the same time to combine professional activity with entertainment content consumption. Manipulative strategies are targeted at a multitasker's mental state, exploiting a new type of subjectivity, namely «content viewers», who want to get an immediate response to a search query. Manipulations involve strategies based on the phenomena of "digital shadow" and "digital legacy". Thus, digital technologies bring into the human being the features of programming, which has a controlling effect [6]. Exerting a governing influence, they appropriate to themselves the role of designers of human life and activity.

A specific type of technological rationality is emerging; it relies on the use of ready-made information resources, borrowing and compiling Internet content. Modernity is saturated with the spirit of this special "technological" rationality. This particular "technological" rationality is based primarily on "digital skills" and digital competencies. To be rational means to enter bravely the space of technological innovation. However, the lack of digital skills and technological competencies gives rise to viewing them as a hostile force.

Technological rationality generates the effect of «borrowed knowledge». This effect, which is evaluated as negative, is associated with the following situation. An individual with digital skills can easily find the necessary information on the Web and assigns it to himself as his personal knowledge. The "borrowed knowledge" effect captures the discrepancy between the highly developed digital skills and digital competencies that the younger generation is characterized by, and their inability to embrace the conceptual basis of cultural heritage. This gap is due to the fact that located on the Network online information does not 
automatically become personal experience. "Content viewers" scan the information in a superficial way, without translating it to personal knowledge. Cognitive acts of observation in the conditions of the info-world have a clip character. Therefore, the "borrowed knowledge" effect leads to cognitive deformations. Borrowing web content destroys reflexivity, it is replaced by intensive absorption of information and the exchange of information messages. In this connection, the question arises, how to turn the indication of information into the quality of the subject's internal experience and consciousness? Researchers call this situation "the hard problem of content" [7]. Moreover, it should also be emphasized that the rapid development of new technologies requires, firstly, the continuous improvement of digital skills, and, secondly, it creates the need to "reassemble" them with regard to every new situation.

\section{ANTHROPOLOGICAL TRANSFORMATIONS TOWARDS "CONVERGENCE OF SUBJECTIVITY"}

The scholars unanimously agree that the Man of the Future should be able to operate with a significant amount of interrelated information and managing network content. However, it should be noted that the mutual penetration of one's digital skills and network resources leads to "the convergence of subjectivity". Thus, the starting point of research is the question, how can we explain the process of convergence of subjectivity in the conditions of digitalization?

The focus of attention is shifted to the problem of convergence, reflecting the process of combining the natural intellectual abilities of a person and the capabilities of network practices and artificial systems. In our opinion, we should keep in mind two meanings of the concept of "convergence of subjectivity. First of all, as we have been emphasized earlier, the words combination "convergence of subjectivity" means the synthesis and integration of the subject's digital skills, on the one hand, and the Network capabilities and resources, on the other hand [8]. In fact, each of us finds ourselves in this situation in our daily life.

At the same time, in the second meaning, the concept of "convergence of subjectivity" points to the symbiosis of subjects of natural-physical type and Artificial Intelligence (AI), Artificial Super Intelligence (ASI). Human and technological integration is taking place. The adepts of this process are seen in the symbiosis of man and digital technologies a new era in the history of mankind. So, A.Clark emphasizes that «it is worth considering that what really matters might be just the fluidity of the human-machine integration and the resulting transformation of our capacities, projects, and lifestyles. First, we care about the potential of technology to become integrated so deeply and fluidly with our existing biological capacities and characteristics that we feel no boundary between ourselves and the nonbiological elements. Second, we care about the potential of such human-machine symbiosis to transform (for better or for worse) our lives, projects, and capacities» $[9]^{\mathrm{p} .23}$. The scientist is sure that the line between biological self and technological world was, in fact, never very firm. Clark's prediction is as follows: «over the next seventy-some years you and your software agents are locked in a complex dance of co-evolutionary change and learning, each influencing, and being influenced by, the other. You come to expect and trust the input from the agents much as you expect and trust the input from your own unconscious brain. In such a case and in a very real sense, the software entities look less like part of your problem-solving environment than part of you. The intelligent system that now confronts the wider world is biological-you-plus-thesoftware-agents» [9].

In fact, the intelligent systems that have entered modern life and are considered the main product of artificial intelligence, largely exceed the natural capabilities of humans. Increasingly, they are delegated the functions of the main agent of modern human life. Intelligent systems and computer memory provide a number of benefits. For example, intelligent systems have put new methodological tools at their service - Big Data technologies. Big Data- technologies are rated as "a technological macro-trend for transforming social actions into online quantitative data". The turn towards danification is obvious, and scientists record a data-driven approach and a shift to research, which are controlled by the data [10]. A new criterion is approved, declaring that "data is everything». The style of modern network thinking is largely determined by this new criterion.

A review of "Coming of age: A review of embodiment and the neuroscience of semantics" examines the ideas of convergence in the context of neuropsychological approaches to embodied [11]. The interdisciplinary approach incorporated into our methodological strategy allows us to use and interpret the key ideas of these studies. Such a key 
point is the "embodied knowledge" associated with the understanding that the mind interacts with the body as well as with the environment. In other words, the role of the bodily organization and the experience of the body's interaction with the environment (and in this case, the digital environment) are taken into account in the functioning of various cognitive processes. The environment has to be internalized somehow. Metaphorically speaking, it is necessary to "push the world inside the mind". According to the researchers, the embodied approaches do very well for on-line action between a body and an environment, and offer some explanations about how the environment is utilised to benefit cognition. The authors identify the "convergance zones" in association cortices and believe that patterns of activity in higher order "convergance zones" do act as stand-alone representations. However, begs the question of whether a fully analogue system as proposed by strong embodiment? [11 $]^{\mathrm{p} .44}$. After all, an analog system inevitably loses some of the richness and complexity of the sensory experience. While the strong embodiment proposes 'full simulation' - the re-enactment of sensory and motor activations (to a greater or lesser degree) produced during real experience. While the strong embodiment proposes 'full simulation' - the reenactment of sensory and motor activations (to a greater or lesser degree) produced during real experience.

In the context of our study, it is necessary to focus on the negative consequences of the interactions of "a person - the Network", "a person - Internet resources". In this regard, we are closer to the integrated approach, which includes the environment as part of the cognitive system and the situation of the cognitive subject located in it [12]. It is important to emphasize that, since in the digital environment, a person transfers a huge part of the cognitive load to technological search engines, priority is given to digital competencies, which are necessary to access online resources. Digital skills are the most important tool for "expanding people" and their capabilities in the digital world. At the same time, one should not forget that, firstly, network interactions position themselves as a selfsufficient type of being, replacing real connections and relationships with simulative analogs. Secondly, the online world has a strong attraction. And, thirdly, as a rule, a modern person acts as a "Content Viewer". It is logical to assume that these circumstances cause transformations of the consciousness of a modern person, which are due to the network capabilities of reducing the perceived world to its schematic, simplified and fragmentary virtual representations.

\section{CONCLUSION}

The study showed that large-scale digital interactions contribute to the emergence of a new type of determination that determines human behavior, cognitive and psycho-emotional states. The general negative effect of digital determination is due to the replacement of physical reality with analog- digital projection and virtual imitation of the external world. The Internet space generates many quasi-real events and simulative images, which leads to significant deformations of both the system of collective perception and human selfawareness. The main vector of anthropological transformations indicates the convergence of natural intellectual abilities of a person and the possibilities of digital technologies. The "face to the screen" life, which become the norm in the era of the pandemic, sets the superpersonal scale of control and coercion. Subjects of the digital age turn out to be agents of network practices, content viewers, multitaskers. It should be emphasized that network interactions position themselves as a selfsufficient type of being, replacing real connections and relationships. However, it is a fact that any analog system inevitably loses some of the wealth and complexity of the sensory experience.

As we assume, anthropological transformations can be traced in several directions. Firstly, this subordination of the individual's vital activity to digital algorithms and manipulative network coverage. A person finds himself in a situation of total imposition of meanings. Secondly, the digital world imposes new digital values, which in fact turn out to be pseudo-values. Among the values of the digital world are "network success", the number of "likes" and followers, "digital image", "digital footprint", as well as Internet slang. The style of modern network thinking is largely determined by a new criterion proclaiming that "data solves everything". Thirdly, since an individual transfers a huge part of the cognitive load to information search engines, a specific type of technological rationality is formed. This type of rationality is associated with the borrowing and appropriation of Web content. It gives rise to the effect of "renting knowledge". Full immersion in the content of algorithmic digital reality frees a person from the need to think and take responsibility for your actions. 
In general, in the context of large-scale digitalization, anthropological transformations include: the vector of virtual activity for commercial purposes; the vector of satisfying the need to simulate an "embodied" existence; the vector of getting pleasure from virtual reality. Reflection is replaced by participation in information events and surfing over the Web. Behavior patterns that are not accompanied by comprehension and understanding are becoming widespread. All these shifts lead to the emergence of a new paradigm of human existence, which is burdened with significant negative consequences, both long-term and short-term.

\section{AUTHORS' CONTRIBUTIONS}

This paper is independently completed by Tatyana Leshkevich, including conceptualization, methodology, investigation, writing - original draft preparation, writing - review, editing, resources and identification of new types of subjectivity of the digital era, detection of a new form of rationality, fixing the effect of "borrowed knowledge", development of the convergence problem.

\section{REFERENCES}

[1] T.G. Leshkevich, Digital transformations of the epoch in the projection of their impact on modern man, in: Tomsk State University Journal, 2019. no. 439, pp. 103-109. DOI: https://doi.org/10.17223/15617793/439/12

[2] T. Leshkevich, A. Motozhanetz, Worldview through the Prism of Personal Life-Meaning Orientations, in: Philosophia, Springer, 2021, pp.1-11 DOI: https://doi.org/10.1007/s11406020-00314-2

[3] J. Baudrillard, The Gulf War will not take place, In: Baudrillard, J. The Gulf War did not take place (trans. P. Patton). Bloomington, USA: Indiana University Press, 1995, pp. 2329.

[4] E. Ruppert, J. Law, M. Savage, Reassembling Social Science Methods: The Challenge of Digital Devices, In: Theory, Culture \& Society, Special Issue on The Social Life of Methods, 2013, 30 (4), pp. 22-46.

[5] R. Collins, The Sociology of Philosophies: A Global Theory of Intellectual Change. Cambridge: Harvard University Press. 1998.
[6] D. Rushkoff, Program or be Programmed. Ten Commands for a Digital Age, OR Books, New York. 2010. DOI: $10.2307 /$ j.ctt207g7rj

[7] D. Hutto and E. Myin, Radicalizing Enactivism: Basic Minds without Content. Cambridge, MA: MIT Press. 2013. DOI: https://doi.org/10.1093/analys/ant102

[8] T. Leshkevich, The Vector Of Methodology Modification: Convergence Of Sociohumanitarian Knowledge With Post-nonclassics", in: Tomsk State University Journal, 2018, № 427, pp. 71-78. DOI: https://doi.org/10.17223/15617793/427/9

[9] A. Clark, Natural-Born Cyborgs: Minds, Technologies, and the Future of Human Intelligence. Oxford, England, Oxford University Press, 2004, pp. 23-31.

[10] S. Ceri, On the Big Impact of "Big Computer Science", in: Werthner, Hannes, van Harmelen, Frank (Eds.), Proceedings 11th European Computer Science Summit (ECSS 2015), Vienna, October, 2015, pp. 17-16. DOI: https://doi.org/10.1007/978-3-319-55735-9

[11] L. Meteyard, S. Cuadrado, B. Bahrami, and G. Vigliocco, Coming of age: A review of embodiment and the neuroscience of semantics, in: Cortex; a Journal Devoted to the Study of the Nervous System and Behavior, 2010, vol. 48(7), pp. 788-804. DOI: 10.1016/j.cortex.2010.11.002

[12] A. Myachykov, C. Scheepers, M. Fischer and K. Kessler, TEST: A Tropic, Embodied, and Situated Theory of Cognition, In: Topics in Cognitive Science, 2013, Jul: 6(3), pp. 442460. DOI: $10.1111 /$ tops. 12024 